\title{
Investigation on the Deterioration Mechanism of Tuff Stones Used for the Exteriors at the Former Koshien Hotel
}

\author{
Koki Yamada ${ }^{1, *}$, Chiemi $\mathrm{Iba}^{1}$, Tomoko Uno ${ }^{2}$, Kazuma Fukui ${ }^{1}$, and Daisuke Ogura ${ }^{1}$ \\ ${ }^{1}$ Kyoto University, Department of Architecture and Architectural Engineering, Graduate school of Engineering, Kyotodaigakukatsura \\ Nishikyo-ku, Kyoto, 615-8540, Japan \\ ${ }^{2}$ Mukogawa Women's University, Department of Architecture, 1-13 Tozaki-cho Nishinomiya, Hyogo, 663-8121, Japan
}

\begin{abstract}
The former Koshien Hotel is an historic Japanese architectural structure, where two different tuffs called Nikkaseki and Tatsuyamaishi were used to build the exterior. Despite its cultural significance, the building's exterior is deteriorating in many ways, with water permeation being the main factor. In this study, the hygrothermal properties of both Nikkaseki and Tatsuyamaishi were measured in order to examine the correlation between deterioration mechanisms and the tuff characteristics in detail. The basic physical properties, pore size distribution, vapor permeability, hydraulic conductivity, and sorption isotherm were measured. The results of a comparison of two tuffs led us to hypothesize that the main reason behind Nikkaseki's deterioration is expansive freezing, while that of Tatsuyamaishi is caused by repeating dehydration or dry-wet cycles.
\end{abstract}

\section{Introduction}

The former Koshien Hotel, Hyogo Prefecture, Japan, is an historic architectural structure built in 1930, designed by Arata Endo, a Japanese contemporary of Frank Lloyd Wright. At the former Koshien Hotel, two tuffs, Nikkaseki and Tatsuyamaishi, were used for the building's exterior, and they suffer from deterioration characterized by lump exfoliation and fine peeling off, respectively. The typical deterioration patterns of Nikkaseki and Tatsuyamaishi are respectively shown in Figs. 1 and 2. Historic architectural structures in modern Japan commonly have exteriors made of porous materials such as tiles, stones or bricks. In these materials, moisture that has penetrated the pores is often found to cause some material deterioration, and the tuff used for the former Koshien Hotel exterior is not an exception. However, effective conservation methods have not been established, especially for tuff. Since these material deteriorations do the most harm to the original stones, which are culturally valuable, our main goal is to clarify the mechanisms of Nikkaseki's lump exfoliation and Tatsuyamaishi's peeling off.

Nikkaseki consists of a yellow tuff stone that is also called Kanagasoishi, and these materials were also used for historic Japanese architectural structures, such as the interior of the National Diet Building of Japan. However, the only quarry, located in Komatsu city, Ishikawa Prefecture, recently closed. Tatsuyamaishi is a yellowgrey tuff quarried in Takasago city, Hyogo Prefecture, and this material was also used for the stone walls at Himeji Castle. Tatsuyamaishi is also becoming more difficult to quarry for high-quality products. Therefore, these two tuffs, which are valuable as cultural assets, require urgent protection from deterioration.

Therefore, this study aims to clarify the deterioration mechanisms of both tuffs, focusing on the moisture transfer inside the tuffs, especially in areas with high moisture content, typically rainwater penetrating the materials. We first investigated the current state and environmental conditions of the site mainly through field surveys and weather data. We also conducted measurements of material properties of the two tuffs, including their hygrothermal properties. At the end of this paper, we discuss the deterioration mechanisms based on the results.

\section{Current state of tuffs and local climatic conditions}

We have examined the repair records, present state of damage, and the environmental conditions of the former Koshien Hotel using field surveys so far. According to the repair records, though several types of water repellents were applied and mortar was sometimes used as a filler for cracks, these treatments have not sufficiently prevented material deteriorations. The reason for the failure of these treatments remains uncertain because water penetration is only one possible cause for the deterioration. Furthermore, even if water penetration is the cause, what is happening inside wet materials has yet to be determined.

The field survey reveals that the tuff exterior at the former Koshien Hotel suffers from various forms of deterioration, such as algae growth, salt deposition, color changes, and surface damaging.

\footnotetext{
* Corresponding author: yamada.koki.28m@st.kyoto-u.ac.jp
} 

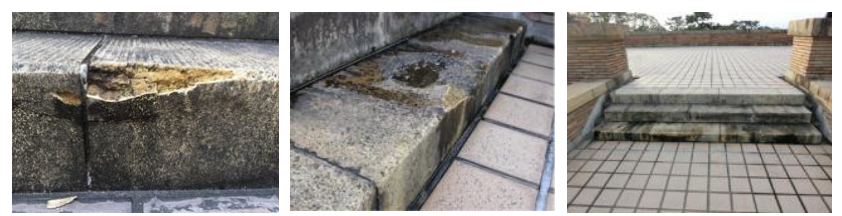

Fig. 1. Lump exfoliation of Nikkaseki at rooftop steps. (2018)
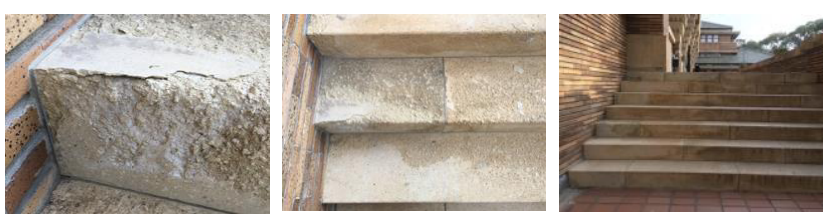

Fig. 2. Tatsuyamaishi finely peeling off at steps. (Jan. 2019)

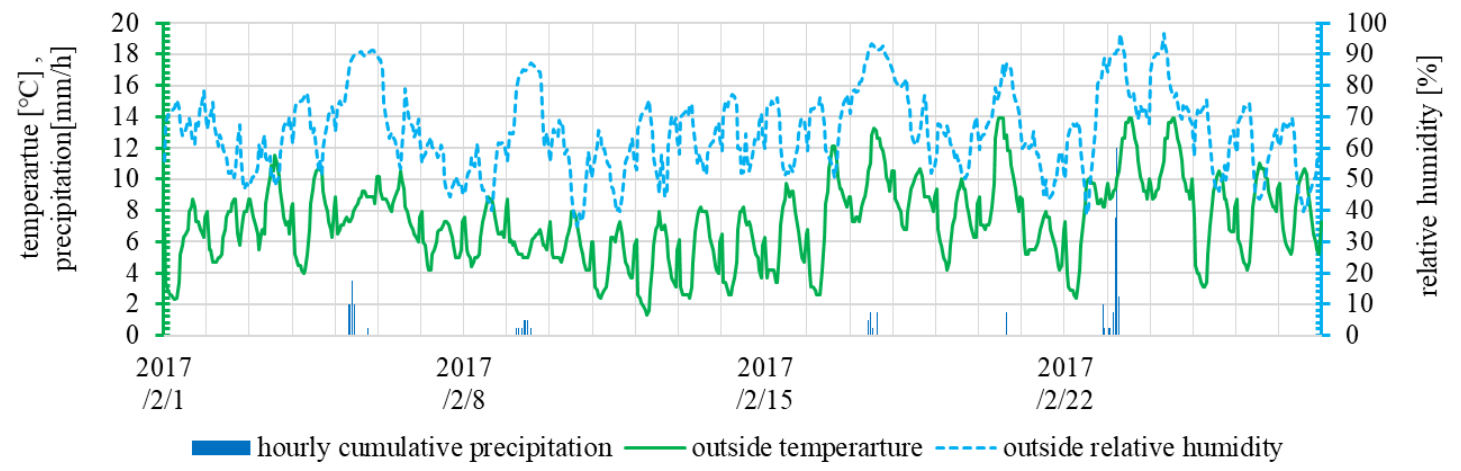

Fig. 3. Hourly ambient air temperature, relative humidity, and precipitation during Feb. 2017.

In particular, the Nikkaseki block used for the steps of the staircase at the rooftop, open to the sky, is severely damaged; the stones exfoliate in a lump, as displayed in Fig. 1. The figure also shows that some rainwater remained on the tread surface even a few days after precipitation. In contrast, the Tatsuyamaishi block is finely peeling off mostly at the treads of the staircase in the southern part of the building under eaves, where the materials are not directly exposed to rainwater, as seen in Fig. 2. The deterioration patterns are specific to each tuff.

The air temperature and relative humidity $(\mathrm{RH})$ were measured at the site, and the precipitation data were provided by Nishinomiya City [1]. According to the data, the annual local climate follows the typical moderate climate pattern in Japan. Figure 3 illustrates the outdoor temperature and $\mathrm{RH}$ with the hourly cumulative precipitation data in February 2017. The site only reached temperatures below the freezing point a few days per year, based on estimates from the 20112019 data on Kobe and Osaka (two cities that nearly interpose Nishinomiya City) from the Japan Meteorological Agency [2]. However, it was inferred that the surface of the Nikkaseki staircase at the rooftop might have reached the freezing point because of nocturnal radiant cooling. The temperature drop on the surface is estimated to be $-4 \sim 5{ }^{\circ} \mathrm{C}$, according to the equation for nocturnal radiation (effective radiation) developed by Brunt's formula at a horizontal surface [3]:

$$
q=-\varepsilon_{\mathrm{w}} \sigma T_{o}^{4}(0.474-0.0065 \sqrt{f})
$$

where $q$ is the net incident long-wave radiation $\left(\mathrm{W} / \mathrm{m}^{2}\right), \varepsilon_{\mathrm{w}}(=1)$ is the supposed radiant emissivity of the surface, $\sigma$ is the Stefan-Boltzmann Constant $(=5.67 \times$ $\left.10^{-8} \mathrm{~W} / \mathrm{m}^{2} \mathrm{~K}^{4}\right), T_{o}$ and $f$ are the temperature $(\mathrm{K})$ and the vapor presure $(\mathrm{Pa})$ of ambient air, respectively. The equivalent temperature of radiation is calculated by dividing $q$ by $\alpha$ which stands for the total heat transfer coefficient $\left(=23 \mathrm{~W} / \mathrm{m}^{2} \mathrm{~K}\right)$.

\section{Methods of the material properties measurements}

To examine tuff deterioration mechanisms, we needed to understand the transport phenomena and accumulation of heat and moisture inside materials. We conducted several measurements against both tuffs to ascertain the material properties, including basic physical properties, vapor permeability, hydraulic conductivity, and the sorption isotherm. These properties are required not only to discuss the cause of deterioration but also to perform upcoming hygrothermal simulation. In addition, pore size distribution has great significance when discussing moisture related phenomena. Non-weathered tuff samples were used in all experiments in this paper.

\subsection{Dry density and water content at saturation}

First, the basic physical properties, dry density, and water content at saturation of Nikkaseki and Tatsuyamaishi were measured in a laboratory. Dry density was determined by calculating the average values of three $5 \mathrm{~cm} \times 5 \mathrm{~cm} \times 15 \mathrm{~cm}$ samples for Nikkaseki and three $4.8 \mathrm{~cm} \times 4.6 \mathrm{~cm} \times 12 \mathrm{~cm}$ samples for Tatsuyamaishi after drying at $105{ }^{\circ} \mathrm{C}$. Volumetric water contents at saturation under normal pressure and under a vacuum were measured using more than three samples for each tuff by weighing the samples.

\subsection{Thermal Conductivity}

Thermal conductivity in both dry- and vacuum-saturated states was measured using the hot wire method [4] on two of the three samples of the dry-density measurements for each tuff. The experiment was performed using a QTM-500 quick thermal conductivity meter (Kyoto Electronics Manufacturing CO., LTD.) at a constant temperature room of $23 \sim 24{ }^{\circ} \mathrm{C}$. 


\subsection{Pore size distribution}

To undertsand the pore size distribution of Nikkaseki and Tatsuyamaishi, mercury intrusion porosimetry was performed within the range of $0.0018 \sim 100 \mu \mathrm{m}$ in radius, using an AutoPore IV9520 porosimeter (Micromeritics Instrument Corp.). The average pore radius and cumulative pore volume were measured with the condition of 480 dynes $/ \mathrm{cm}(=0.48 \mathrm{~N} / \mathrm{m})$ for mercury surface tension and $140^{\circ}$ for contact angle between the samples and the mercury. The samples were dried for 4 hours at $120^{\circ} \mathrm{C}$ before the measurement.

\subsection{Vapor permeability}

The permeability to water vapor was measured by the cup method [5]. The samples and the experimental setup are shown in Fig. 4. The thicknesses of the Nikkaseki and Tatsuyamaishi samples were determined to be 16.3 $\mathrm{mm}$ and $15.5 \mathrm{~mm}$, respectively, by averaging the thickness at the four corners. The sample weights were $206.4 \mathrm{~g}$ and $344.3 \mathrm{~g}$, respectively, and the permeable surface area was regulated to $81 \mathrm{~cm}^{2}$. Higher RH was controlled at $85 \%$ with a saturated $\mathrm{KCl}$ solution, while the lower side (outside the cups) was at $53 \%$ with aqueous $\mathrm{Mg}\left(\mathrm{NO}_{3}\right)_{2} \cdot 6 \mathrm{H}_{2} \mathrm{O}$. These $\mathrm{RH}$ values were set because we needed vapor permeability in the hygroscopic area, where water vapor flow still dominates the moisture transfer, but we also had to focus on relatively high moisture content areas simultaneously because the deterioration seems to occur in damp or wet states. The vapor pressure difference between the interior and exterior of the cups was $1076 \mathrm{~Pa}$. The experiment was performed under a constant temperature of $23^{\circ} \mathrm{C}$.
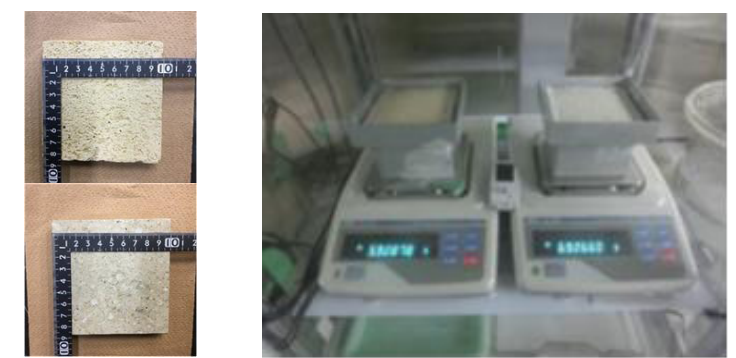

Fig. 4. Tuff samples and experimental setup for the cup method.
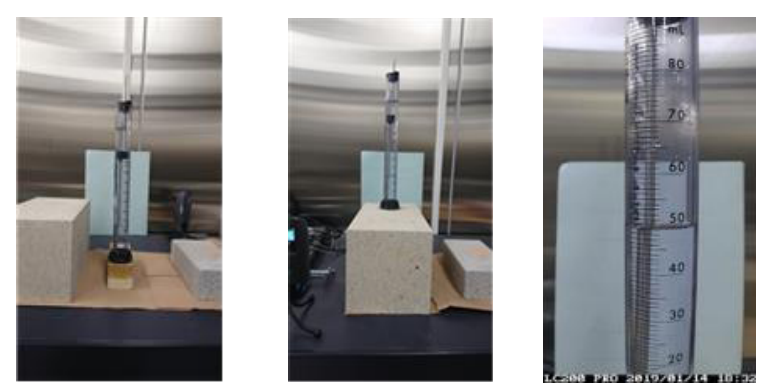

Fig. 5. Hydraulic conductivity measurements using an infiltrometer; left: Nikkaseki, middle: Tatsuyamaishi.

\subsection{Hydraulic Conductivity}

To determine water conductivity of building materials in this study, we attempted to perform a quick measurement using a mini disc infiltrometer (METER Group.), an instrument used to evaluate the hydraulic conductivity of unsaturated soil, to estimate water penetration without deteriorating the samples much more easily.

By applying an exponential model for unsaturated soil created by Nachabe and Illangasekare (1994) [6], hydraulic conductivity can be described as a function of water chemical potential for free water $\mu(\mathrm{J} / \mathrm{kg})$, which depends on temperature $T(\mathrm{~K})$ and $\mathrm{RH} \varphi(-)$. The equations are described below.

$$
\begin{gathered}
\mu=\mathrm{R}_{\mathrm{v}} T \ln (\varphi) \\
K(\mu)=K_{\text {sat }} \exp \left(\alpha \mu \rho_{\mathrm{w}} / 98.0642\right)
\end{gathered}
$$

where $R_{v}$ is the gas constant for water vapor $(\mathrm{J} / \mathrm{kgK}), \rho_{\mathrm{w}}$ is the water density $\left(\mathrm{kg} / \mathrm{m}^{3}\right)$, and $K_{\text {sat }}$ and $\alpha$ are the saturated hydraulic conductivity $\left(\mathrm{m}^{3} / \mathrm{msmH}_{2} \mathrm{O}\right)$ and the sorption number $\left(\mathrm{cm}^{-1}\right)$, respectively, which can be calculated by comparing infiltration speeds recorded at two different suction levels.

The apparatus used can adjust the suction on the surface of the samples within $-0.5 \mathrm{~cm}$ to $-7.0 \mathrm{~cm}$ (corresponding to around $\mu=-0.05 \sim-0.7 \mathrm{~J} / \mathrm{kg}$ ). For Nikkaseki, the infiltration speed was measured at -0.5 $\mathrm{cm}$ and $-3.0 \mathrm{~cm}$ suction; for Tatsuyamaishi, at the results were $-0.5 \mathrm{~cm}$ and $-7.0 \mathrm{~cm}$. The apparatus is shown in Fig. 5 with the samples. The Nikkaseki sample was about $5 \mathrm{~cm} \times 5 \mathrm{~cm} \times 15 \mathrm{~cm}$, and the Tatsuyamaishi sample was about $15 \mathrm{~cm} \times 15 \mathrm{~cm} \times 30 \mathrm{~cm}$.
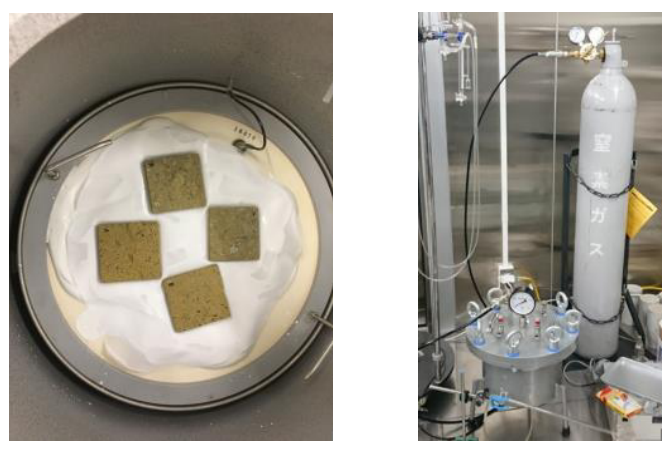

Fig. 6. Tuff samples for the pressure plate method (left); nitrogen gas and an autoclave for pressure plate method (right).

\subsection{Sorption isotherm}

The sorption isotherm was measured in three ways. For the area high in moisture content, the pressure plate method [7] was used during the moisture desorption process. For the hygroscopic region, the static desiccator method of water [8] and the gas adsorption method [9] were employed for the moisture adsorption process.

As shown in Fig. 6, two Nikkaseki samples (about 50 $\mathrm{mm} \times 50 \mathrm{~mm} \times 5.5 \mathrm{~mm}$ ) and two Tatsuyamaishi samples (about $48 \mathrm{~mm} \times 46 \mathrm{~mm} \times 6 \mathrm{~mm}$ ) were used for the pressure plate method. The samples were vacuum 
saturated before the measurement, and the pressure inside the chamber was regulated at $0.1 \mathrm{MPa}, 0.35 \mathrm{MPa}$, $0.5 \mathrm{MPa}$, and $0.75 \mathrm{MPa}$ (each corresponding to $99.93 \%$, $99.74 \%, 99.63 \%$, and $99.45 \% \mathrm{RH}$, and $\mu=-95.8$, $-356.2,-507.2$, and $-754.6 \mathrm{~J} / \mathrm{kg}$ ) by nitrogen gas.

For the static desiccator method of water, saturated aqueous solutions of $\mathrm{MgCl}_{2} \cdot 6 \mathrm{H}_{2} \mathrm{O}, \mathrm{Mg}\left(\mathrm{NO}_{3}\right)_{2} \cdot 6 \mathrm{H}_{2} \mathrm{O}$, $\mathrm{NaCl}, \mathrm{KCl}$, and $\mathrm{Na}_{2} \mathrm{SO}_{4}$, were used to control $\mathrm{RH}$, corresponding to $33 \%, 53 \%, 75 \%, 85 \%$, and $94 \%$, respectively, under $23{ }^{\circ} \mathrm{C}$. All samples used were about $25 \mathrm{~mm} \times 25 \mathrm{~mm} \times 5 \mathrm{~mm}$, and each tuff was measured by putting two samples in an RH desiccator. The tuffs were started weighed from a dry condition $\left(105^{\circ} \mathrm{C}\right)$.

The gas adsorption method was performed with a BELSORP-max volumetric gas adsorption instrument (MicrotracBEL Corp.) under the water vapor adsorption conditions at the temperature of $23{ }^{\circ} \mathrm{C}$. The tuff samples were crushed into small pieces in order to put them into a test-tube. The measurement process was as follows: The sample was 1) heated at $40^{\circ} \mathrm{C}, 2$ ) vacuumed for 30 min., 3) heated into $100{ }^{\circ} \mathrm{C}$ and settled to an isothermal steady state, and 4) dried at $100{ }^{\circ} \mathrm{C}$ for $10 \mathrm{~h}$ under a vacuum, with 5) an electric furnace being removed. After removing the furnace, the samples were kept steadily until the measurements.

\section{Results of the material properties measurements and discussions}

\subsection{Dry density and water content at saturation}

The basic physical properties of the two tuffs are shown in Table 1 and Fig. 7. Tatsuyamaishi has about twice the dry density of Nikkaseki, and the vacuum moisture content indicates that the total volume of pores is considerably larger in Nikkaseki. The moisture content of Tatsuyamaishi was less compared to the values estimated from the other methods we performed. This is partly because the samples were relatively large $(4.6 \mathrm{~cm}$ $\times 4.8 \mathrm{~cm} \times 3 \mathrm{~cm}$ ), which led to insufficient degasification.

\subsection{Thermal Conductivity}

The results of thermal conductivity measurement for dry and wet samples are also displayed in Fig.7. Thermal conductivity was higher in Tatsuyamaishi, but the increasing rate from the dry to the saturated conditionwith moisture contents of $0.488 \mathrm{~m}^{3} / \mathrm{m}^{3}$ for Nikkaseki and $0.135 \mathrm{~m}^{3} / \mathrm{m}^{3}$ for Tatsuyamaishi-was larger in Nikkaseki, which suggests that Nikkaseki's temperature becomes more susceptible to outdoor air temperature when wet.

Table 1. Basic physical properties.

\begin{tabular}{|c|c|c|}
\hline & Nikka & Tatsuyama \\
\hline dry density $\left[\mathrm{kg} / \mathrm{m}^{3}\right]$ & $1177 \pm 38.4$ & $2257 \pm 38.8$ \\
\hline $\begin{array}{c}\text { moisture content at } \\
\text { saturation under atmospheric } \\
\text { pressure }\left[\mathrm{m}^{3} / \mathrm{m}^{3}\right]\end{array}$ & $0.467 \pm 0.026$ & $0.078 \pm 0.007$ \\
\hline $\begin{array}{c}\text { moisture content at } \\
\text { vacuum saturation }\left[\mathrm{m}^{3} / \mathrm{m}^{3}\right]\end{array}$ & $0.485 \pm 0.014$ & $0.084 \pm 0.007$ \\
\hline
\end{tabular}
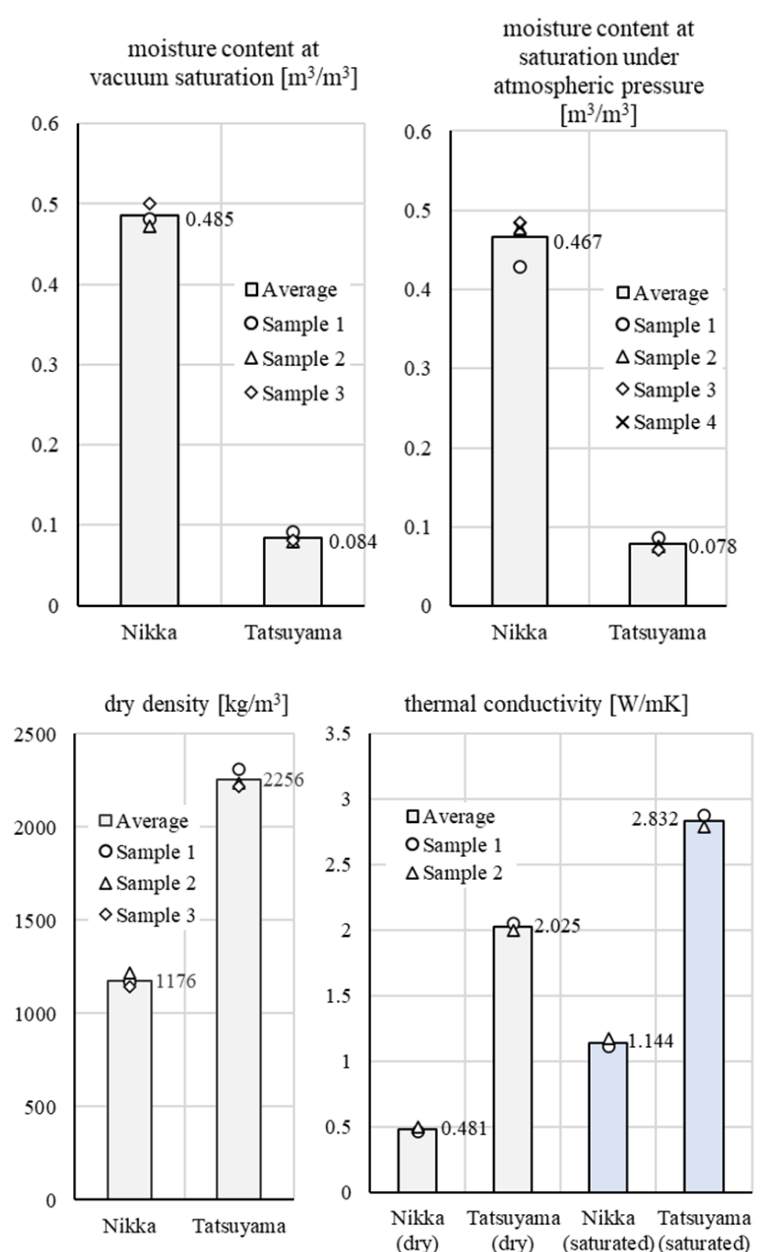

Fig. 7. Basic physical properties and thermal conductivity.

\subsection{Pore size distribution}

The results of mercury intrusion porosimetry (Fig. 8 and Table 2) showed that Nikkaseki has both the mode pore radius and a cumulative pore volume which were larger than those of Tatsuyamaishi. The cumulative pore volume values $\left(\mathrm{m}^{3} / \mathrm{m}^{3}\right)$ were calculated by using dry density. Nikkaseki's mode pore radius was near $0.2 \mu \mathrm{m}$, while that of Tatsuyamaishi was around $0.06 \sim 0.07 \mu \mathrm{m}$.

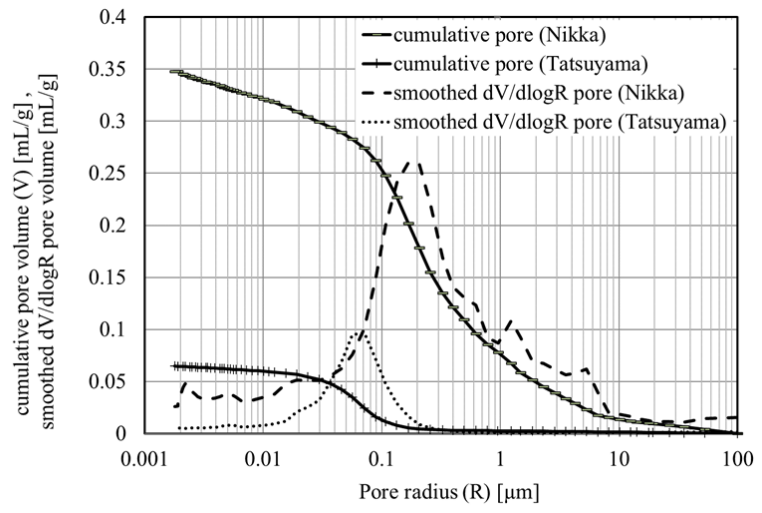

Fig. 8. Pore size distribution of Nikkaseki and Tatsuyamaishi. 
Table 2. Pore size data from mercury intrusion porosimetry.

\begin{tabular}{|c|c|c|}
\hline & Nikka & Tatsuyama \\
\hline average pore radius $[\mu \mathrm{m}]$ & 0.035 & 0.027 \\
\hline cumulative pore volume $[\mathrm{mL} / \mathrm{g}]$ & 0.35 & 0.065 \\
\hline cumulative pore volume $\left[\mathrm{m}^{3} / \mathrm{m}^{3}\right]$ & 0.412 & 0.147 \\
\hline
\end{tabular}

\subsection{Vapor permeability}

The permeability of water vapor of the two tuffs is shown in Table 3. The Nikkaseki value was about 3.8 times larger than that of Tatsuyamaishi, under the given temperature and humidity conditions. This difference can be explained simply by the difference in pore size distribution and total pore volumes; Nikkaseki had larger pore radii and pore volumes, allowing it to transfer water vapor more easily than Tatsuyamaishi.

Table 3. Cup method results.

\begin{tabular}{|c|c|c|}
\hline & Nikka & Tatsuyama \\
\hline water vapor transfer rate $[\mathrm{kg} / \mathrm{s}]$ & $1.37 \times 10^{-8}$ & $3.79 \times 10^{-9}$ \\
\hline $\begin{array}{c}\text { water vapor transmission resistance } \\
{\left[\mathrm{m}^{2} \mathrm{sPa} / \mathrm{kg}\right]}\end{array}$ & $6.35 \times 10^{8}$ & $2.39 \times 10^{9}$ \\
\hline water vapor conductivity $[\mathrm{kg} / \mathrm{msPa}]$ & $2.56 \times 10^{-11}$ & $6.76 \times 10^{-12}$ \\
\hline
\end{tabular}

\subsection{Hydraulic Conductivity}

Using a mini disk infiltrometer, the hydraulic conductivity curves of the two tuffs shown in Fig. 9 were obtained with the sets of parameters displayed in Table 4. Nikkaseki had a relatively high hydraulic conductivity compared to Tatsuyamaishi when mostly saturated, but their value relation switched around $\mu=-3.0 \mathrm{~J} / \mathrm{kg}$.

By comparing the two tuff measurement results, Nikkaseki seemed to decrease its hydraulic conductivity significantly when $\mu$ dropped. On the other hand, Tatsuyamaishi could conduct larger amounts of water when it is relatively dried.

The high hydraulic conductivity of Tatsuyamaishi in the relatively low water chemical potential region was probably due to the fact that Tatsuyamaishi had more fine pores than Nikkaseki, as shown in Fig. 8. Tatsuyamaishi pores made the water capillary effect occur at much lower RH values. Moreover, the reason the Nikkaseki $K_{\text {sat }}$ value is higher than that of Tatsuyamaishi is that Nikkaseki has larger average pore radii and pore volumes.

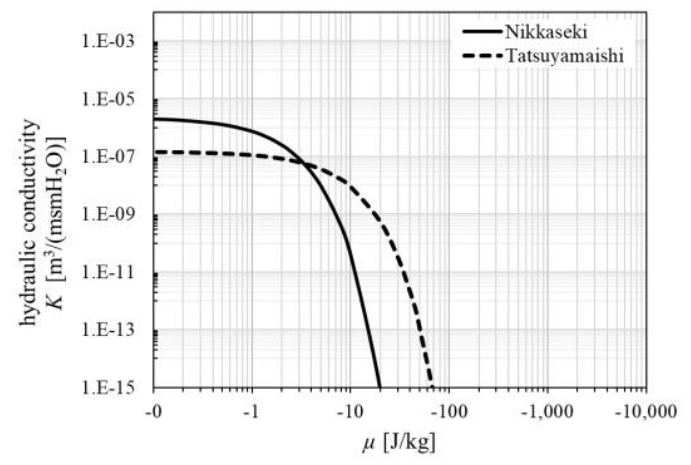

Fig. 9. Hydraulic conductivity of both tuffs calculated from the measurements using a mini disk infiltrometer.
Table 4. Parameters of hydraulic conductivity function.

\begin{tabular}{|c|c|c|}
\hline & Nikka & Tatsuyama \\
\hline $\begin{array}{c}\text { hydraulic conductivity } \\
\text { (saturated) } K_{\text {sat }}[\mathrm{m} / \mathrm{s}]\end{array}$ & $2.20 \times 10^{-6}$ & $1.44 \times 10^{-7}$ \\
\hline sorption number $\alpha\left[\mathrm{cm}^{-1}\right]$ & 0.017 & 0.0275 \\
\hline
\end{tabular}

\subsection{Sorption isotherm}

From the pressure plate method, four plotted points in the high moisture content region were obtained. The results were averaged over the two samples, as shown in Table 5. Nikkaseki's moisture content heavily dropped among the $0.35 \sim 0.05 \mathrm{MPa}$ suction range, while that of Tatsuyamaishi remained nearly stable in the whole range measured. This finding suggests that the drop in Tatsuyamaishi's suction curve exists in the lower moisture content area.

The results of the static desiccator method are shown in Table 6, and the results of the gas adsorption method are plotted with those of the other measurements in Fig. 10. Here the data from gas adsorption method are plotted under $93 \% \mathrm{RH}$ because the water vapor condensation in the sample seemed to occur incidentally during the measurement in the high humidity region above $93 \%$ RH.

Comparing the three different measurement experiments, the results in the high moisture content area (pressure plate method) seemed to be smoothly connected with each curve from the lower content area (static desiccator method and gas adsorption method), regardless of whether the curve was for a desorption process or an adsorption process. In addition, it was inferred that the maximum moisture content change occurred around $\mu=-1,000 \sim-10,000 \mathrm{~J} / \mathrm{kg}$ for both tuffs, supporting the idea that, within the range of $\mu$ shown in Fig. 9, both tuffs were almost saturated.

For the Tatsuyamaishi curve, the results of the latter two measurements for the adsorption process were almost the same when plotted, and the sorption isotherm was partly determined. However, Nikkaseki did not show a similar tendency, while the moisture content due to gas adsorption was about triple of that of the desiccator method. This difference seems to have appeared because we had to crush tuff samples into small pieces in order to perform the gas adsorption method, which may have caused the samples to have a larger accessible surface area at the ruptured surface. Although the two curves are different, their gradients within the range of $\mu=-10,000 \sim-100,000 \mathrm{~J} / \mathrm{kg}$ are similar, which may be a typical pattern for Nikkaseki.

Table 5. Moisture content resulting from the pressure plate method.

\begin{tabular}{|c|c|c|c|c|}
\hline suction & $\mu$ & $\mathrm{RH}$ & \multicolumn{2}{|c|}{ moisture content $\left[\mathrm{m}^{3} / \mathrm{m}^{3}\right]$} \\
\cline { 4 - 5 }$[\mathrm{MPa}]$ & {$[\mathrm{J} / \mathrm{kg}]$} & {$[\%]$} & Nikka & Tatsuyama \\
\hline 0.00 & - & - & 0.4470 & 0.1348 \\
\hline 0.10 & -95.8 & 99.93 & 0.3574 & 0.1319 \\
\hline 0.35 & -356.2 & 99.74 & 0.3508 & 0.1300 \\
\hline 0.50 & -507.2 & 99.63 & 0.3133 & 0.1281 \\
\hline 0.75 & -754.6 & 99.45 & 0.2694 & 0.1248 \\
\hline
\end{tabular}


Table 6. Moisture content resulting from the static desiccator method.

\begin{tabular}{|c|c|c|c|}
\hline \multirow{2}{*}{$\mu[\mathrm{J} / \mathrm{kg}]$} & \multirow{2}{*}{$\mathrm{RH}[\%]$} & \multicolumn{2}{|c|}{ moisture content $\left[\mathrm{m}^{3} / \mathrm{m}^{3}\right]$} \\
\cline { 3 - 4 } & & Nikka & Tatsuyama \\
\hline-8458.4 & 94 & 0.0434 & 0.0181 \\
\hline-22216.3 & 85 & 0.0371 & 0.0104 \\
\hline-39326.1 & 75 & 0.0327 & 0.0113 \\
\hline-86787.7 & 53 & 0.0275 & 0.00689 \\
\hline-151553.9 & 33 & 0.0224 & 0.00591 \\
\hline
\end{tabular}
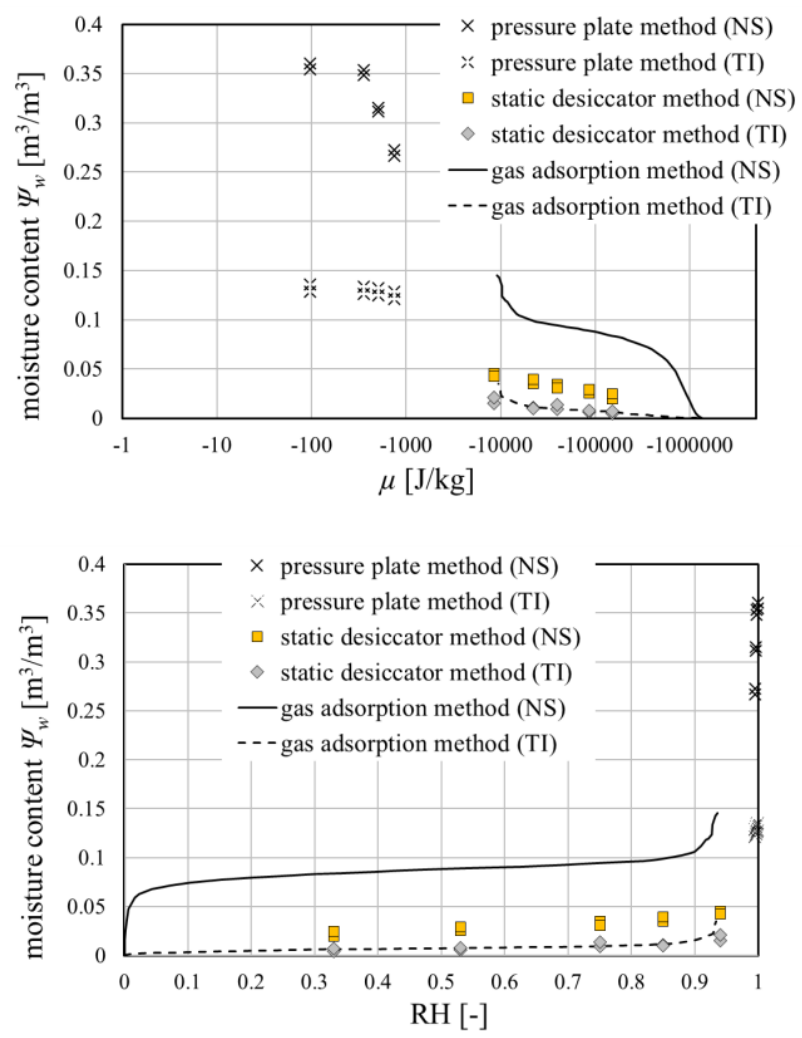

Fig. 10. Sorption isotherm by $\mu$ (above) and by relative humidity (below) of Nikkaseki and Tatsuyamaishi.

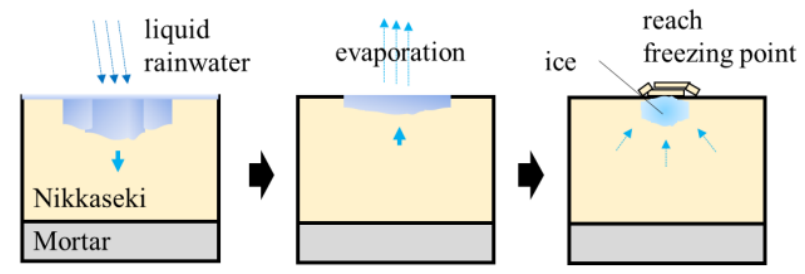

Fig. 11. Assumed mechanism of Nikkaseki exfoliation.

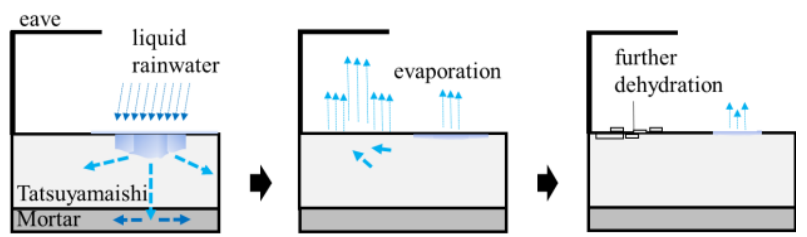

Fig. 12. Assumed mechanism of Tatsuyamaishi peeling off.

\section{Discussion}

Based on the experimental results, the difference of the two tuff's properties seemed to lead to the difference in their deterioration patterns.

For Nikkaseki, three factors related to the deterioration were indicated from the field survey and laboratory experiments. First, Nikkaseki is exfoliating in a lump at the rooftop staircase, which is directly exposed to rain and has a larger sky view factor, leading to larger nocturnal radiant cooling, and rainwater remains on its surface for a few days after rainfall. Second, there was a period in which the nighttime air temperature was regularly near $2{ }^{\circ} \mathrm{C}$. Since the surface temperature was estimated to be $4 \sim 5{ }^{\circ} \mathrm{C}$ below the air temperature, and considering the influence of radiant cooling, Nikkaseki's exterior temperature may have reached below the freezing point near the surface several times in winter. Third, according to the measurement results, Nikkaseki's hydraulic conductivity seemed to drop significantly when its moisture content decreased, as compared to Tatsuyamaishi.

Therefore, we assume that the mechanism of Nikkaseki exfoliation follows the process shown in Fig. 11. Exterior Nikkaseki staircase steps retain rainwater after rainfall. However, when evaporating, hydraulic conductivity decreases rapidly as the moisture content decreases, and rainwater is trapped inside the material for several days. When the ambient temperature reaches around $4{ }^{\circ} \mathrm{C}$ in this period, the material reaches the freezing point near the surface, and the volume increase due to ice formation leads to some exfoliation of the material at a relatively larger scale. Similar deterioration mechanisms have been occurring on Japanese roof tiles [10].

In contrast, Tatsuyamaishi was found to be peeling off finely at the staircase steps, especially in areas with eaves that are not directly exposed to rain. In addition, the tuff also showed a relatively high hydraulic conductivity level at lower moisture content areas when compared to Nikkaseki, which implies that penetrated moisture can easily evaporate and does not become trapped inside the material for a longer time span.

From these examinations, the abrasion of Tatsuyamaishi is estimated to be mainly caused by an effect of over-dehydration or dry-wet cycles, as shown in Fig. 12. In this case, rainwater infiltrates the tuff exterior from the rain-exposed side, which is the southern half of the staircase. However, the stone can transfer moisture horizontally to the tuff surface under the eaves because of the high hydraulic conductivity. Since the area without exposure to rain has less water supply, evaporation occurs notably here, drying the tuff surface. The likeliness of repeating this process is assumed to be a factor behind the peeling off observed in the Tatsuyamaishi sample, which leads to over-dehydration or salt deposition, for example. Such deterioration by wetting and drying on the tuff has been recorded in laboratory experiments [11].

As shown in the two figures, Nikkaseki exfoliation is estimated to be the result of freezing, and Tatsuyamaishi peeling off stems from drying. However, we have to note 
that these hypotheses were only made by comparing the two different tuff properties with each other, and further research is required. To identify the hydraulic conductivity in detail, numerical simulation needs to be performed, by comparing with the results of gamma-ray attenuation methods measuring water sorption in building materials. In the simulation, we use the hygrothermal properties which we measured in this paper. As a next step, some deterioration experiments such as freeze-thaw test for both kinds of tuff are needed to examine the deterioration hypothesis presented in this paper. Furthermore, the numerical analysis of heat and moisture transfer in the tuffs under the actual climatic conditions using the measured material properties should be performed to understand the deterioration process in detail.

\section{Conclusion}

In order to reveal the mechanisms of Nikkaseki exfoliation and Tatsuyamaishi peeling off at the former Koshien Hotel building exterior, field surveys and some hygrothermal property measurements were executed.

Considering the results of local environmental investigations and experiments mainly related to water transfer, the relations between these deteriorations and the tuff moisture properties were discussed. Consequently, Nikkaseki was assumed to be exfoliating by freezing, while Tatsuyamaishi appeared to be peeling off by dehydration, indirectly. However, the examination was only based on research on environmental conditions and some limited property measurements against nonweathered tuff samples. Therefore, further studies are required against the hygrothermal behaviours in detail using a numerical analysis.

This study was partly supported by JSPS KAKENHI JP17K06641.

\section{References}

1. http://nishinomiya.tenki.ne.jp/

2. http://www.data.jma.go.jp/obd/stats/etrn/index.php

3. D, Brunt, Notes on radiation in the atmosphere. I, Quar. J. Met. Soc., Vol. 58, pp.389-420 (1932)

4. ISO 8894-2: Refractory materials - Determination of thermal conductivity - Part 2: Hot-wire method (parallel) (2007)

5. ISO 12572: Hygrothermal performance of building materials and products - Determination of water vapour transmission properties - Cup method (2016)

6. M.H. Nachabe, and T. Illangasekare, Use of Tension Infiltrometer Date with Unsaturated Hydraulic Conductivity Models, Grnd. W. Vol. 32, No. 6, pp. 1017-1021 (1994)

7. ASTM C1699 - 09 Standard Method for Moisture Retention Curves of Porous Building Materials Using Pressure Plates (2015)
8. ISO 12571: Hygrothermal performance of building materials and products - Determination of hygroscopic sorption properties (2013)

9. ISO 9277: Determination of the specific surface area of solids by gas adsorption - BET method (2010)

10. C. Iba, A. Ueda, S. Hokoi, Field Survey on frost damage to roof tiles under climatic conditions, Struct. SURV. Vol. 34, pp.135-149 (2016)

11. A.B. Yavuz, Durability assessment of the Alaçatı tuff (Izmir) in western Turkey, Environ. Earth Sci. Vol.67, pp.1909-1925 (2012) 